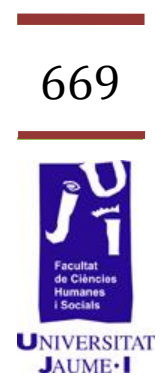

\title{
Revistas Postismo y La Cerbatana, inicio de la poesía de vanguardia en la posguerra española
}

José Rafael Mesado Gimeno

rafamesado@hotmail.com 
I. Resumen

Este trabajo pretende establecer, como si de un ejercico de arqueología poética se tratase, el inicio de la poesía de vanguardia en el contexto socio-cultural de la posguerra española. En el entramado de la territorialidad poética de la primera posguerra establecido por las revistas literarias, las publicaciones Postismo (1945) y La Cerbatana (1945) significaron el abandono de la poesía de signo realista, tanto de la poesía oficial como de la poesía comprometida, y supusieron el enlace de la literarura y del arte español con los movimientos vanguardistas exteriores. En ellas se halla el germen de la poesía vanguardista en la literatura española.

Palabras clave: posguerra, poesía, vanguardia, surrealismo, experimentación, letrismo, postismo.

\section{Introducción}

Este artículo surge de la tesis doctoral titulada Convergencias. Carlos Edmundo de Ory y la poesía de la marginalidad, dirigida por Don Santiago Fortuño Llorens, que trata de establecer la relación de la poesía oryana con los poetas estadounidenses de la Beat generation y con el pensamiento underground y sus antecedentes. Por ello, son importantes las aportaciones del movimiento postista, del que Carlos Edmundo de Ory fue uno de sus integrantes, ya que significan el rechazo de la cultura oficial de la posguerra española y la apertura hacia parámetros literarios más acordes con el panorama cultural exterior.

De hecho, las dos revistas editadas por el movimiento postista, y prohibidas por la censura, marcan, junto a las aportaciones de poetas como Juan Eduardo Cirlot o Joan Brossa, el inicio de la poesía de vanguardia en la posguerra española.

\section{Inicio de las poéticas tras el desastre}

Tras la guerra, abatido el país por la cruzada de liberación nacional, queda un páramo devastado: tabula rasa cultural, desertización extrema provocada a sangre y fuego, exterminio del enemigo pasado por el filtro ideológico. Ello implica la condena de la vanguardia, la excomunión de todo elemento cultural relacionado con los oscuros deseos freudianos, el atrincheramiento ante el surrealismo vinculado con el comunismo, el ataque a toda experimentación de signo dadaísta o cubista, relacionada con la idea de terrorismo libertario y cultural, y el exterminio de toda literatura combativa y social. Para el poder, la intelectualidad resulta 
sospechosa. Pablo Neruda, Pablo Picasso, Luis Buñuel, Rafael Alberti y una extensa nómina de artistas e intelectuales consiguen el estatuto de figuras malditas para el nuevo régimen.

En la geografía poética el silencio se va fracturando. Desde varias grietas surge la expresión poética y crea su propia territorialidad ideológica y poética. ${ }^{1}$ Son las revistas literarias la apertura de estas grietas. El franquismo toleró su existencia, ya que su pequeño radio de acción no entrañaba ningún peligro. Algunas publicaciones tuvieron el apoyo institucional, otras la mirada de la sospecha dirigida hacia ellas. Lo cierto es que la censura permitió, hasta cierto punto, la proliferación de publicaciones con el afán de tener su control. Ahora bien, también se intervino de forma taxativa. Tanto la revista Postismo como su sucesora La Cerbatana, vehículos de expresión de movimiento postista, fueron prohibidas. El poder no podía tolerar la existencia de un movimiento artístico que mantenía abiertas relaciones con el surrealismo francés, ya que el franquismo asociaba surrealismo y comunismo desde que André Breton en el Segundo manifiesto del surrealismo (1929) acercara sus postulados a la defensa del proletariado. De todos modos, la revista literaria era el espacio perfecto para la expresión de la poesía prohibida o exiliada debido a su pequeño circuito de difusión. En ellas podían aparecen poemas de Julio Salinas, de Rafael Alberti o de Juan Ramón Jiménez junto a otros poetas extranjeros prohibidos sin que ello comportase ningún efecto de relevancia social. En la revista Espadaña se publicaron las «Nanas de la cebolla» escritas en la cárcel por Miguel Hernández y que gracias a Antonio Buero Vallejo, que las sacó del penal, pudieron surgir al espacio público. Revistas como Insula (1946) o Índice (1946) significaron el enlace con los poetas del exilio. También la revistas suponían la existencia de un espacio para la experimentación y el punto de contacto con la vanguardia más radical. Este espacio fue ocupado por las revistas Postismo y La Cerbatana, que establecieron un gesto rupturista, radical y enérgico con la expresión poética coetánea a la manera del grupo dadaísta de Zurich y del grupo surrealista de París. Las revistas supusieron, al mismo tiempo, un espacio de apertura hacia el exterior, un contacto con los poetas coétaneos extranjeros. En definitiva, las revistas cumplieron varios objetivos y sirvieron como espacio de difusión, de intercambio y de expansión de las poéticas establecidas bajo la dictadura en todas las direcciones. Funcionaron como elemento dispersor de las prácticas poéticas y de los postulados teóricos. En sus editoriales, proclamas, manifiestos o declaraciones aparecía el discurso teórico de las diferentes direcciones poéticas.

\footnotetext{
${ }^{1}$ Las revistas Gracilaso (1943), de signo clasicista e imperial, Corcel (1942) y Proel (1944) que proclaman una poesía humana y neorromántica, o Espadaña (1944), precursora de la poesía social, marcan el territorio de la poesía realista y oficial. La poesía de la marginalidad está representada por la revista, de tendencia esteticista, Cántico (1947) y por las revistas Postismo (1945) y La Cerbatana (1945), que suponen la reactivación de la vanguardia.
} 
Es en las revistas del grupo postista donde la proclama, la declaración de intenciones y el mainifesto toman un talante más importante y radical, siguiendo los modelos ofrecidos por las publicaciones vanguardistas europeas, americanas o peninsulares como Les Soirées de París (1912) dirigida por Guillaume Apollinaire, Dada (1917) auspiciada por Tristan Tzara, 391 (1917) ${ }^{2}$ por Francis Picabia, Les Champs Magnétiques (1919) de André Breton y Philippe Soupault, las revistas dirigidas por el grupo surrealista Littérature (1919), La Révolution surréaliste (1924), Minotaure (1933) y Documents (1933) dirigida por Georges Bataille, Perseo (1919), Reflector (1920) dirigida por Guillermo de Torre, VLTRA (1921), Prisma (1922), Proa (1922) dirigida por Jorge Luis Borges y Macedonio Fernández, Creación (1924), Martín Fierro (1925) fundada por Eva Méndez, Plural (1925), Un enemic del poble (1917) editada por JoanSalvat Papasseit o la portuguesa Orfeu (1915).

Lo que caracterizó a las revistas poéticas de la primera posguerra fue el eclecticismo. Aunque cada publicación marcó las líneas territoriales que articularon la geografía poética, en sus páginas se ofrecía un espacio a poetas situados en otros márgenes poéticos. Así en Cántico publicaron Jesús García Nieto, el poeta garcilacista por excelencia, y Carlos Edmundo de Ory, el más heterodoxo de todos los poetas. En Espadaña publicaron poetas paradigmáticos de la vanguardia como Juan Eduardo Cirlot o Gabino Alejandro Carriedo junto a representantes de la poesía más tradicional como Dionisio Ridruejo, José Garcia Nieto o Luis López Anglada. En Postismo apareció un caligrama escrito y acompañado por una tarjeta triangular, a imitación de la utilizada en la presentación de esta revista, con los nombres de sus autores, Rafael Montesinos, José María Valverde y Jesús Juan Garcés, poetas cuya poesía se hallaba alejada de los derroteros vanguardistas. Jesús Juan Garcés publicó en La Cerbatana sus Poemas primitivos para ángeles, poética que se erige como elemento precursor del concretismo poético. También Juan Ramón Jiménez publicó el poema "Una y él" siguiendo unos parámetros parecidos. Para Carlos Edmundo de Ory, estos poetas, cuya procedencia nada tiene que ver con el movimiento, forman, en cierto sentido, parte del Postismo. Acerca del primero Ory nos dice, en la Historia del postismo (Grande, 1970 a: 270), que:

Este oficial de Garcilaso se alejó de sus cuarteles para pedir entrada en nuestro manicomio. Nos traía sus "Poemas primitivos para ángeles" y le dejamos pasar.

Para Félix Casanova de Ayala, como nos dice en 1964 en su artículo titulado "Teoría y páctica del postismo", Jesús Juan Garcés es «un garcilacista recién incorporado al postismo» (Pont, 1987: 542). A Juan

${ }^{2}$ Sólo cuatro números de esta revista, escrita en francés, se publican en Barcelona, cuya redacción y administración se hallaban domiciliadas en las Galerías Dalmau. La revista se editó posteriormente en Nueva York de la mano de Francis Picabia y Marcel Duchamp. 
Ramón Jiménez, Ory lo describe como «un elegíaco panteísta andaluz» y escribe sobre ello lo siguiente en la Historia del postismo (Grande,1970 a: 267):

Yo no tengo nada que ver con Juan Ramón (salvo una influencia natural adolescente), lo que no es óbice para que Juan Ramón hiciera "postismo", sin saberlo yo; Juan Alcaide Sánchez nos envió el poema titulado "Una y él" de Juan Ramón Jiménez, interrogándose sobre su posible "postismo", y como lo consideramos, en efecto, verdaderamente postista, lo publicamos en La Cerbatana.

La revista Garcilaso, paradigma del clasicismo poético más retrógrado, supuso, en cierta medida, un espacio abierto donde publicaron poetas cuya poesía pertenecía a territorios muy alejados de sí. En sus páginas aparecieron poemas de poetas consagrados, como Gerardo Diaego o Dámaso Alonso, hasta de los poetas heterodoxos, como Eduardo Chicharro o Carlos Edmundo de Ory. En este sentido, Santiago Fortuño (2008: 44) señala el caracter divulgativo y acogedor de la revista, que ofreció sus páginas a muchos poetas que luego criticaron severamente su labor.

Este elemento ecléctico se dio, sobre todo, en las publicaciones de la primera posguerra. En todas ellas aparece una triple dimensión: la impronta teórica, el eclecticismo marcado por las colaboraciones y las traducciones poéticas. Más tarde las revistas acotaron mucho más su territorio especializado. Entre las revistas aparecidas en la posguerra, cuyo espacio abarca la poliédrica geografía poética, cabe destacar las siguientes: Escorial (1940), Corcel (1942), Garcilaso (1943), Proel (1944), Espadaña (1944), Índice (1945), Verbo (1945), Postismo (1945), La Cerbatana (1945), Insula (1946), Cántico (1947), Planas de Poesía (1947), Acanto (1947), La isla de los ratones (1948), Cuadernos Hispanoamericanos (1948), Deucalion (1951), Papeles de Son Armadans (1956), Primer Acto (1957), La trinchera (1962), Problemática 63 (1963), Claraboya (1963), Poesía 70 (1968), Fablas (1969), Aquelarre (1970), Trece de Nieve (1971), Poliedros (1972), Marejada (1973).

Las revistas Postismo y La Cerbatana fueron los canales de expresión del movimiento postista. En ellas aparecieron sus escritos programáticos y sus expresiones artisticas y literarias, entre ellas la poesía.

\section{Postismo}

La revista Postismo se editó en enero de 1945 como órgano programático del movimiento postista. La financiación corrió a cargo de Silvano Sernesi. De la maquetación se encargó Eduardo Chicharro, ayudado por Jaime Pol Girbal. Eduardo Chicharro fue también el redactor jeje ("redactor jefe postista"), el cargo de director fue ocupado 
indistintamente por Carlos Edmundo de Ory y Silvano Sernesi. La Redacción estaba situada en la Calle Barbieri, $n$ ㅇ 10, de Madrid, en el local de la imprenta GAMA, Artes Gráficas S. A. El precio de la publicación era el dos pesetas.

La revista tiene una estética vanguardista que plásticamente se expresa en el grafismo de signo cubista y futurista, en los dibujos de Benjamín Palencia y de Luis Lasa, en el caligrama en forma de copa escrito por Rafael Montesinos, José María Valverde y Jesús Juan Garcés, y en la fotografía de la portada, en la que aparece en el espacio central una fotografía de Gregorio Prieto con el torso desnudo, con un sombrero sideral y con un naipe flotando sobre su pecho. El título de la revista remite a una ampulosa estética modernista realizada a base de arabescos y racargados trazos florales. También se da en ella la estética naïf en los apartados dedicados a la infancia a través de los dibujos de Tony, el hijo de Eduardo Chicharro y Nanda Papiri, y la caligrafía infantil. Toda la estética postista está reflejada en la portada de la revista: el sombrero futurista que apunta a la vanguardia, la desnudez que señala la pretendida ingenuidad y el naipe que señala el elemento lúdico.

Postismo supone un espacio pluridimensional. Ofrece los elementos teóricos del movimiento, sus prácticas estéticas tanto pictóricas como literarias (poéticas, narrativas y teatrales), una mirada poliédrica a la vanguardia y un acercamiento al mundo mágico de la infancia. Participan en la publicación, además de los tres agentes postistas, Benjamín Palencia, Wenceslao Fernández Flórez y Tomás Borrás.

La revista ofrecía las claves del movimiento en sus escritos programáticos, sobre todo, en el Primer Manifiesto del Postismo, que funciona como una proclama que señala las convergencias del movimiento con el dadaísmo, el surrealismo y el expresionismo. Los escritos programáticos son los siguientes: "España lanza el Postismo", "Primer anuncio del Postismo al mundo", Primer Manifiesto del Postismo y "En el que el lector que leyere verá cosas quizás más de nuestro interés que de su agrado, y otras posibilidades que se sugieren".

El primero, situado en la primera página y firmado por La Dirección, define de manera exageradamente provocativa el Postismo como un movimiento ampilo y plural. El segundo, que aparece en páginas segunda y tercera es una entrevista realizada en noviembre de 1944 a los autores postistas. El Primer Manifiesto del Postismo, firmado por Eduardo Chicharro y que aparece en las páginas desplegables que se corresponden con las 4-5 y, 12-13, es el escrito más importante, pues supone un decálogo exhaustivo de los postulados del movimiento y su relación con los diversos movimientos vanguardistas coetáneos $y$ anteriores. $Y$ el último, "En el que el lector que leyere verá cosas más de nuestro interés que de su agrado, y otras posibilidades que se sugieren", firmado por La Redacción, ocupa la contraportada y supone algunas aclaraciones 
respecto al surrealismo, al tiempo que señala el humor como componente esencial del movimiento.

El Postismo se define, en la introducción al Primer Manifiesto del Postismo, situada en la página $\mathrm{n}$ - 5 , como un movimiento constituido por su componte teórico y por sus componentes artístico y literario. $Y$ es en las prácticas artísticas donde mejor se encuentra el significado del movimiento.

Un manifiesto establece unas premisas, concreta un credo, denuncia simpatías y antipatías, pero nunca dará, sino en forma abierta y de principio, las normas en detalle de una tendencia. Ingenuo y ligero será quien crea poder hacer Postismo puro después de leídas estas consideraciones. El patrón habrá que buscarlo en las obras, en la obra Postista.

Por ello, la revista ofrece una serie de practicas artísticas, pintura, narrativa y poesía. Esta última está representada por la sección titulada Liricoteca, situada en las páginas octava y novena, compuesta por once poemas y que funciona como primera antología de poesía postista. Se trata de once romances escritos por los tres poetas postistas. Entre ellos cabe destacar el "Romance de Laooconte y la luna " y "El romance del ronquido del niño" de Carlos Edmundo de Ory. En ellos encontramos ya la definición de la poesía postista que consiste en la demolición del edificio poético realista. Ésta se basa en la sonoridad extravagante, la sintaxis barroca distorsionada, la asociación libre de objetos, el lenguaje de la demencia y el humor lúdico. Todos estos componentes pueden observarse en el "Romance del ronquido del niño":

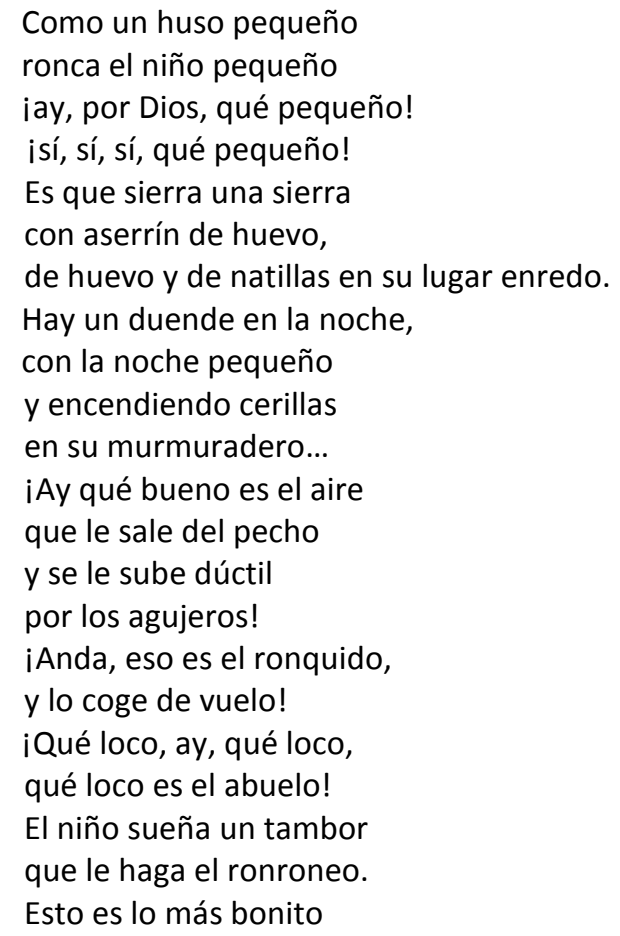


desde Carlyle a Asuero;

mientras su madre duerme,

el niño está durmiendo.

\section{La Cerbatana}

La Cerbatana es la segunda publicación del movimiento postista, ésta aparece meses después de que la censura franquista decretara el cese de la revista Postismo y supone su continuación. La revista lleva un subtítulo, Revista llustrada de la Nueva Estética. La redacción está situada en la misma dirección. Los directores son los tres integrantes del grupo y el Redactor Jefe es Jaime Pol Girbal. La impresión y la tipografía corren a cargo de GAMA, Artes Gráficas S. A. El precio, dos pesetas.

La revista sigue la misma línea artística trazada por su antecesora, que consiste en constituir una mirada plural al apnorama artístico de vanguardia y ser el vehículo portavoz de un movimiento global. Como tal, la revista ofrece los resultados de las prácticas postistas. En este sentido, resulta una revista más literaria que teórica. También toma conciencia de ser un espacio marginal en el horizonte cultural y, a la vez, ello le confiere una dirección más reivindicativa. Eduardo Chicgarro denuncia abiertamente esta situación en su artículo "Nos echan de la poesía", situado en la cuarta página. La revista dedica también un apartado a la magia de la infancia y a la recuperación de esa conciencia naïf.

El grafismo sigue ofreciendo una estética vanguardista donde palabra e imagen entran en una estrecha relación. Para Rafael De Cózar (2005: 117118), La Cerbatana significa la apertura hacia la poesía experimental, basada en la poesía fonética y en la palabra gráfica. La maquetación está mucho más cuidada que en la revista anterior y existe una presencia mayor de los recursos tipográficos. Se juega con los distintos tipos y tamaños de letra en los títulos, los subtítulos, las secciones, los caligramas, los collages... De forma irónica, ello queda señalado en la portada con la frase "iViva Gutemberg!", y de manera más explícita con la geometría de los grafismos. Ya en la portada se observa la importancia de la imagen. En ella aparece sobre un fondo rojo, cortado por el blanco y negro de las líneas trazadas por la palabras, la reproducción de una pintura en blanco y negro de J. Biero. En la contraportada un motivo taurino con caricatura de Manolete dibujado por Luis Lasa muestra sus referencias a la estética vanguardista de signo expresionista. En el interior la imagen supone un constante guiño a la vanguardia. En la primera página encontramos un retrato de una figura femenina, pintada por Benjamín Palencia, cuya estética remite al cubismo y al expresionismo de signo picassiano. En la página decimosexta un dibujo de Carlos Edmundo de Ory conecta con el surrealismo más onírico. En las páginas décima y undécima aparecen dos oleos de Ochoa pintados bajo la estética del simbolismo pictórico. En la tercera página el cuadro de Durero, titulado 
Niño con larga barba, señala el aspecto extraño, misterioso y siniestro del surrealismo. En el artículo, firmado por Eduadro Chicharro, titulado "La patética expresión del arte", situado en la página duodécima, se halla una seleción de pintura que representa las referencias de la pintura postista: Pierre-Auguste Renoir, Nijinski, Gaston Le Roux, Odilon Redon, Georges Braque y Marc Chagall.

La revista ofrece, acorde con el componente plástico presentado en ella, un elemento teórico que respalda las expresiones creativas expuestas. Los textos teóricos son tres. En la página primera se halla, a modo de editorial, el texto firmado por La Dirección y titulado " ¡A la una... a las dos... a las tres!". Se trata de una declaración de principios en la que se reivindica la actitud provocativa, la euforia, el humor, el juego y la locura frente a la rigidez de los valores de la burguesía. En la página cuatro aparece el artículo reivindicativo de Eduardo Chicharro "Nos echan de la poesía", que supone una protesta por la censura sufrida y el silencio impuesto, desde el poder, al movimiento. Más interesante resulta el texto escrito por Silvano Sernesi, que aparece en la undécima página de la revista, titulado "Entrevista a un hombre que se ríe sentado y fuma con la mano y con la boca". En él se propone la exaltación de todas las cualidades que escapan a la lógica, sustento del racionalismo y de la cultura burguesa. Sernesi se apoya en la visión que tuvo André Breton (1962: 29) de un hombre atravesado por una ventana, tal como se indica en el Primer manifiesto del surrealismo, para presentarnos su particular visión recurrente, obsesiva y paranoide. Imagen que rompe con toda lógica y se erige como apertura al absurdo postista. El humo es expulsado al mismo tiempo por la boca y por la mano del hombre que fuma, y ello, precisamente, lo que provoca es la sonrisa en la cara de este ser que se aparece. Ésta es la lógica del Postismo, una lógica que parte del absurdo y se erige como estética paradógica y jovial. Una lógica que, a diferencia del automatismo puro del surrealismo francés, descansa en la voluntad estética.

La revista, más que ser una decálogo de presupuestos teóricos, es una muestra la las prácticas literarias postistas. En ella se ensayan nuevas formas literarias y se proponen nuevas vías de expresión. En la narrativa Silvano Sernesi propone, en su cuento titulado "Casi nos casó Voronoff" una narrativa fantástica con tintes surrealistas que posee conexiones con el realismo mágico. Carlos Edmundo de Ory presenta un fragmento de su novela inédita Mèphiboseth en Onou, diario de un loco y el cuento titulado "La mujer de los tres trapos". Eduardo Chicharro, por su parte, escribe el cuento titulado "Viaje". El texto narrativo más importante viene en la parte interior de la contraportada y está formado por tres cuentos cortos, cada uno firmado por cada uno de los postistas fundacionales. Se trata de un ejemplo de lo que en la actualidad se conoce como microrrelato. Estos textos son, de algún modo, haikus narrativos, poseen 
la poesía, la sugerencia y la ruptura de la lógica propias de los textos japoneses. Como el haiku, transmiten atmósferas. Son, de un lado, un breve susurro al oído, y, a la vez, forman una historia. Pues los tres textos poseen una continuidad narrativa, claro ejemplo de escritura colectiva.

Era una vez de una chiquilla que era muy blanca y se murió y fue más blanca todavía.

Carlos Edmundo de Ory

Luego las campanas se callaron mientras que a su lado terminaban las flores. Era una mañana.

Silvano Sernesi

Buscaba la suerte de un minuto, y la tuvo. Pero luego no recordaba ya en qué había sido.

Eduardo Chicharro

En el género dramático también se ensayan nuevos modelos de expresión, como sería la breve pieza teatral titulada "Historia natural, breve comedia en dos actos", que aparece en la página interior de la contraportada. Se trata de un claro ejemplo de microteatro que tiene sus convergencias con el teatro del absurdo.

Con todo, la poesía es el discurso literario que tiene más presencia. Aquí los tres autores postistas exponen sus experiencias. Eduardo Chicharro presenta, en la página tercera, el poema titulado "De lo más a lo menos", Silvano Sernesi su poema "Anna" en la página décima y Carlos Edmundo de Ory, el "Soneto paranoico" en la página séptima. Este último resulta el más significativo de todos ellos:

Sólo en el mundo con mi media oveja

y una cortada flor en el semblante

bajo la mina honda del diamante

que no tiene raíz ni tiene reja.

Más como soy del odio tenue abeja

manada de algún duende nigromante

peinaré de mi espalda en monte amante

y con heces de concha de la almeja

Mi paranoia de Iolao y Averno,

ihola, pato de oro; hola, marea

donde la mar merece su medusa!...

$Y$ creo que de cebra tengo un cuerno

y de llama un pata panacea

que se gasta en mi alma y que se usa. 
Además la publicación contiene poemas de otros autores. En la página decimoquinta aparecen los poemas "Al niño muerto de Chicharro hijo" de Petito Vella ", "Arlequín asimétrico" de Conrado y un caligrama escrito a mano y que resulta casi ilegible de Manolo Pilares., En la página decimotercera (toda ella forma es un collage a base de la correspondencia recibida, dibujos, textos y manuscritos) aparece el poema titulado "Minero", perteneciente a este último autor, que resulta interesante por su cariz novedoso:

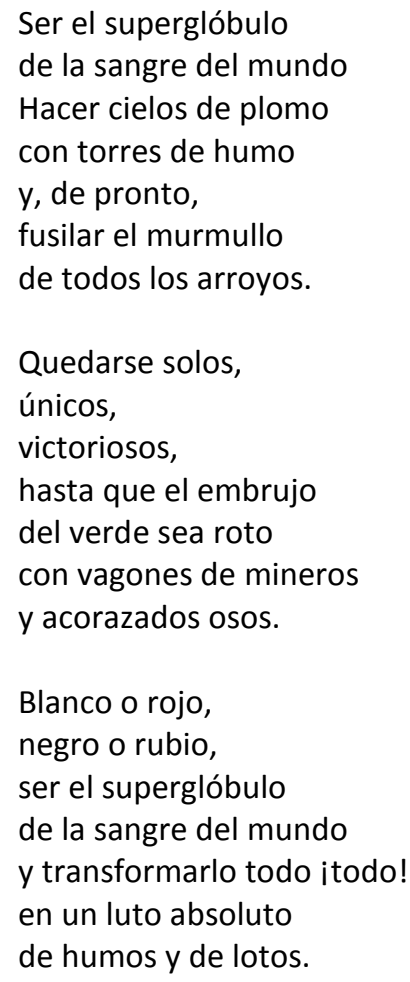

La revista presenta también poemas de poetas más conocidos como el poeta postista Ángel Crespo, Jesús Juan Garcés o Juan Ramón Jiménez. El primero publica en la página número cinco un poema dedicado a Ory titulado "De mi loco al loco de Carlos Edmundo", poema que comporta todos los ingredientes de la poética postista:

Amigo, dulce amigo, dulcilando de luces pegajosas en lo espeso, dándole el beso de la luz al beso y la sombra a la noche le quitando.

Dulcecito de esparto, como Orlando: furioso con la espada y con el peso de un seso sin por qué, casi sin seso, con un perro en la nuca te matando.

Deshojador de hojas deshojadas, matador de los muertos que te esperan en la noche más fría. Desmontadas. 
Tus jinetas cabalgan. ¿Cómo eran?

¿Cómo eran, Dios santo? ¡Qué acabadas,

mi dulcilando amigo, revivieran!

El poema de Juan Ramón Jiménez se titula "Una y él" y aparece en la séptima página. Se trata de un poema de signo experimental que funciona como poema letrista:

\author{
- ¡Ayayay, ayayayi \\ ¿Qué es, di tú, sin amor el vivir? \\ ¡Me querría ahora mismo matar! \\ ¡Ayayay! \\ -Flajinsterio, termifa, cachumbo. \\ ¡Purumpúm, purumpúm, purumpúm! \\ - ¡Ayayay, ayayay! \\ ¿Qué es la vida, di tú, sin amar? \\ ¡Me quisiera ahora mismo morir! \\ ¡Ayayay! \\ -Desidelio, flamina, catumpo. \\ ¡Purumpúm, purumpúm, purumpúm"!
}

Y el poeta Jesús Juan Garcés publica, en las páginas octava y novena, los Poemas primitivos para ángeles. En ellos se observa la presencia de una poesía radicalmente experimental, de signo visual, que recoge las experiencias de la poesía cubista y futurista. Cabe citar alguno de estos nueve poemas para observar la radicalidad de su lenguaje, radical todavía en la nuestra actualidad poética:

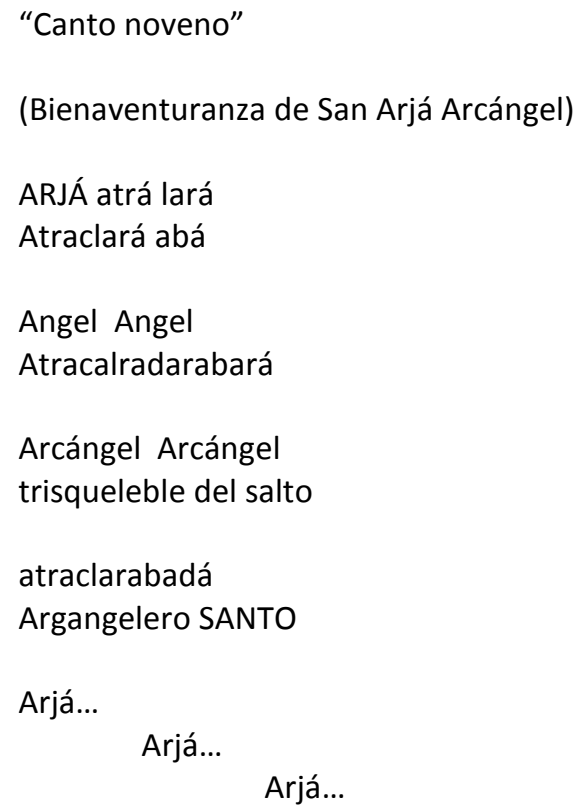

Además, en las mismas páginas en las que se hallan los poemas de Jesús Juan Garcés, se hallan las "Pequeñas fábulas para niños siniestros" de Fernand Marc, que tienen su texto paralelo construido por los postistas 
mediante la técnica del enderezamiento. ${ }^{3}$ Por otra parte, la Redacción publica, en las páginas número cinco y diez, una serie de pulgas, micropoemas realizados a base de frases cortas y directas que remiten a la instantaneidad del haiku y al desconcierto del koan, ${ }^{4}$ a la vez que funcionan como breves aforismos, cuya mirada está puesta en las greguerías de Ramón Gómez de la Serna. Estos textos son los antecedentes directos de los aerolitos de Carlos Edmundo de Ory. ${ }^{5}$ En la página diez aparece el siguiente texto, que sirve como ejemplo:

¡Pobrecillos! Ellos creen que hacen algo bueno porque escriben palabras raras.

Los postistas buscan romper moldes, derribar las barreras que separan los géneros, ensayar nuevos vehículos literarios. Se trata de una escritura libre que intenta realizar una demolición de los códigos literarios imperantes. Para ello se utiliza la transgresión de las normas establecidas, el poder de la imaginación y la práctica del humorismo lúdico.

\section{A modo de conclusión}

En las revistas postistas, publicadas en el año 1945, en plena primera generación de posguerra, se hala la arqueología poética de la poesía renovadora y experimental que llega hasta la actualidad. Poesía heterodoxa para las coordenadas poéticas de la época, que rompe con los cánones de la poesía realista, tanto de signo humanizado como de cariz social. Se trata de una poesía marginal y, también, marginada, tanto desde la cultura oficial como desde los parámetros de la poesía comprometida con el ahora y el aquí de su contexto histórico.

En este sentido, se observan dos direcciones patentes en las revistas postistas. Por un lado, una poesía fuertemente entroncada con el surrealismo francés, que reelabora el material onírico, practica sistemáticamente la extrañeza y encumbra a la imaginación como principal elemento poético. Ésta es la poesía escrita por los poetas postistas. Entre ellos sobresalen Ángel Crespo y Carlos Edmundo de Ory. En ella se halla el antecedente de la poesía de la generación de la década de los setenta del pasado siglo, también conocida como la poesía de los novísimos. Una poesía, de corte veneciano, que supone la revitalización

\footnotetext{
${ }^{3}$ El enderezamiento es una técnica postista mediante la cual se pueden crear, con una serie de mímimas variaciones, infinitos textos a partir de un texto matriz. Técnica que tiene que ver con la práctica de la intertextualidad y de la deconstrucción.

${ }^{4}$ El haiku es una expresión poética propia de la literatura japonesa budista zen que manifiesta una experiencia instantánea de satori o iluminación. El Koan es una especie de paradoja, planteada por el maestro zen al discípulo, para hacer estallar el pensamiento lógico y observar si éste posee el conocimiento más allá de las palabras.

${ }^{5}$ Ory de, Carlos Edmundo, Aerolitos, Madrid, Cuadernos Hispanoamericanos, № 181, enero de 1965; Aerolitos, Madrid, El Observatorio, 1985; Nuevos aerolitos, Madrid, Ediciones Libertarias, 1995; Los aerolitos, Madrid, Calambur, 2005; Novísimos aerolitos, Madrid, Fundación César Manrique, 2009.
} 
del surrealismo y, en cierta medida, la recuperación de la poesía marginal escrita en la posguerra. Entre sus antecedentes cabría señalar el esteticismo poético practicado por el grupo Cántico y la transgresión del movimiento postista. Muchos de sus autores han señalado a Carlos Edmundo de Ory como uno de los grandes poetas maestros y este homenaje se debe, sobre todo, a la heterodoxia de su poesía.

Por otra parte, la poética presentada por Juan Ramón Jiménez y por Jesús Juan Garcés inaugura una poesía de signo experimental, donde el elemento visual, al igual que en el letrismo, resulta fundamental. Esta poesía será continuada por la poesía concreta de Julio Campal, por el experimentalismo del grupo N.O., de las acciones poético-musicales vanguardistas del grupo Zaj, del lenguaje experimental visivo de José Miguel Ullán... Poesía que surge de la conjunción de lo poético con las artes plásticas de vanguardia.

\section{Bibliografía}

BRETON, A. (1962): Manifestes du surréalisme, Jean-Jacques Pauvert Éditeur, Paris (Manifiestos del surrealismo, Visor, Madrid, 2009).

Cozar De, R. (ed.) (1978): C. E. De OrY, Metanoia (1944-1977), Cátedra, Madrid; 2a ed. aumentada, Cátedra, Madrid, 1990.

- (2005): «El Postismo: Revistas Postismo y La Cerbatana» en RuBıo, F. (ed.), Revistas literarias españolas del siglo XX (1919-1975), Vol. II, Olero y Ramos, Madrid.

FoRTuÑo, S. (2008): Poesía de la primera generación de posguerra, Cátedra, Madrid.

GARCÍA DE LA CONCHA, V. (1987): La poesía española de 1935 a 1975. De la poesía existencial a la poesía social 1944-1950, Vol. II, Cátedra, Madrid.

Grande F. (ed.) (1970 a): C. E. De Ory, Poesía 1949-1969, Edhasa, Barcelona.

GRANDE F. (1970 b): Apuntes sobre poesía española de posguerra, Taurus, Madrid.

MilláN, F. Y J. García SÁNCHEZ (1975): La escritura en libertad. Antología de poesía experimental, Visor, Madrid.

PONT, J. (1987): El Postismo, un movimiento estético-literario de vanguardia, Barcelona, Edicions del Mall. 
RuBio, F. (1976): Las revistas poéticas españolas (1939-1975), Turner, Madrid.

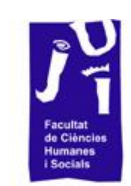


